\title{
The Communication Path of "Non-fiction Literature" in the Context of New Media
}

\author{
Haotian $\mathrm{Su}^{*}$ \\ Liaoning Polytechnic Vocational College, Jinzhou 121007, China
}

Abstract: "Non-fiction" has received much attention as a new form of literature communication, which is closely related to rapid development of domestic mobile internet in recent years. In the context of new media, media convergence has intensified. And online platforms and social media have taken on important task of literature communication, affecting all aspects of modern life. According to different symbols and organizational forms, communication path of "non-fiction literature" in the context of new media can be divided into three paths: digital text, film and television media and sound media.

Keywords: Non-fiction Literature; Digital Text Path; Literature Acceptance

With the development of new media technology, academic circle pays more attention to new media literature centering on online literature year by year. Julia Kristeva, a French scholar, first mentioned "intertextuality" in book Semiotics (in 1969). And based on concept of "cross-textuality", Gérard Genette proposed five levels of intertextuality, metatextuality, hypertext, textuality, and original textuality. These theories provide theoretical cornerstone for development and research of new media literature. Even with traditional broadcasting media, music, stage dialogues and other artistic techniques were borrowed by author, which uses media technology to enhance atmosphere of works. The method of integrating art will become the biggest feature of development of electronic media texts, which further opens literature researchers' horizons.

\section{New media and non-fiction writing}

In 2017, Liang Hong, a writer who doubted fictitious life, published her first fictional work The Light of Guangzheng Liang after she published "non-fiction literature" and China in Liangzhuang seven years later. Known as "non-fiction writing dream factory", one experimental team broke up on October 11, 2017. And the symbolic organization of non-fiction writing is dissolved. In new media era where website traffic is king, non-fiction writing began to ebb in printing and publishing industry. But through network new media, non-fiction writing realized success through website traffic, also appeared some web celebrity and big V in new media era. And the popularity degree even surpasses network literature gods in early stage unprecedentedly.

In April 2017, a text titled I am Yusu Fan appeared on internet, and circle of friends was blown up. The "Noon Story", which launched this article, became a well-known WeChat public platform of "non-fiction writing". At the beginning of September, the website launched Sad of Bullfrog, and then became hot article of 10+ on internet. However, non-fiction web hot article that can continue to write are rare really.

The concept of "non-fiction literature" was introduced to China in the 1980s. It has been over 30 years since then. Before, the different understanding of authenticity of "non-fiction" leads to different ways of "non-fiction" literary cognition. However, from grand narrative based on nationalism to popular writing in new media era, by closing to the folk and pursuing of "good stories" writing way, now "non-fiction" writing has changed way of real description.

This is an open-access article distributed under the terms of the Creative Commons Attribution Non-Commercial License (http://creativecommons. org/licenses/by-nc/4.0/), which permits unrestricted non-commercial use, distribution, and reproduction in any medium, provided the original work is properly cited. 
The "non-fiction writing" platforms and public account have received extensive attention on internet, which includes Hedgehog Commune, "People with Stories", "Noon Story", "One Lab", Freezing Point, Southern People Weekly, and Guyu Story of Tencent. In new media era, the popularity and pursuit of "non-fiction writing" originated from pursuing popular culture in post-modern era and recognition of aesthetic appreciation of daily life. With improvement of education level, the interaction between readers and authors contributes to the emergence of "audience" in popular culture era. And audience's involvement in text writing is deepening day by day. For example, many hot articles often say that "We believe that masters in the folk, welcome everyone to share your ideas by leave messages". It expects that the audience participate in writing and supplement, and finally promote transformation of traditional media non-fiction writing. "The network impact and advanced technology have a great influence on traditional media." Also it impacts traditional class writing teaching.

\section{New media communication path construction of non-fiction literature}

At the beginning of non-fiction literature rising, digital text reading is one of the most important forms of reading literature for readers. However, since the birth of online literature, digital reading has already entered people's view. With social media rising, digital reading path covers more groups now, and it is no longer just youth group's choice in today. The proportion of aged people has been greatly improved. At present, digital path and mobile path depend on Internet to a large extent and have very distinct characteristics.

The era characteristics of new media make digital path become the most important communication path of nonfiction literature. From the perspective of national superstructure, the trend of film and television and digitization of literature field has been strengthened, which has led to reform of management institutions, and realizes comprehensive management of literature publishing and network. It reflects close correlation between "non-fiction literature" field and digital path from the side. From the perspective of economic market, literature communication has created new economic characteristics in digital communication path, appearing Internet occupation of "new media operation". In new media era, it emphasizes the importance of digital operation. And "non-fiction literature" grasps this opportunity and realizes the transformation of official identity. In this section, in order to study characteristics of "non-fiction literature", the path of mobile digital text is refined into mobile reading applications, WeChat, Weibo, and PC.

\subsection{WeChat path}

In the field of literature communication, known as mobile media, mobile phones and IPADs are often used as compensatory media for computer networks in modern society, which can be said to be social media. For example, Weibo is significant closed to a large extent, while WeChat platform can compensate for this deficiency. For ordinary WeChat public accounts, there is clear limit on the number of sending messages each day. Only a few public accounts authorized by WeChat platform do not have limit, which effectively avoids homogenization of communicating content of Weibo. Non-fiction literature communication has opened up various spatial modes on WeChat, such as text and video, which has made great achievements in public accounts such as "Horizon Non-Fiction", "True Story Plan" and "Chinese Sandwich". In addition, Southern People Weekly, Guyu Story, Human's World and other non-fiction WeChat public accounts also gained high attention and achieved good literary communication effect.

The source of WeChat public account of non-fiction literature is very broad. In response to trend of paper readers' age faults, literature publishing organizations are expanding new media actively, thereby, it can further attracts young readers' interest. For this, many magazines such as Southern Weekend and People have adopted modern media directly, opened public account on WeChat, accumulated a large number of fans, and continued to maintain effective activity of public account.

\subsection{Weibo path}

In current Chinese social media, Weibo is one of the biggest platforms. Therefore, Weibo plays a very important role in communication of some non-fiction literature. In terms of communication path of non-fiction literature, we must pay attention to the research of Weibo path. At present, the main Weibo platforms are Sina, Sohu, NetEase and Tencent in China, of which, Sina Weibo has the largest user traffic.

From the genre of "non-fiction literature", most of content spread by Weibo is simple and concise, some of which 
are chicken soups for the soul. Besides, some works of film and television stars and image collections are generally more clicked. This is because non-fiction literature has limited appeal to audiences. However, for shallow reading, fast reading and fashion style of Weibo social platform, it makes "non-fiction literature" difficult to express essential text quality. On the other hand, the communication of "non-fiction literature" on Weibo end reflects long-standing prose and quotation style of some traditional literature. These characters, which had disappeared in current context, have combined with Internet popularization into a new communication path. Meanwhile, in this context, the content expressed by text also has certain changes, which are embodied in emotional theme, content and map culture, language poetry, hardcover book, emphasis on star recommendation and shock effect. For example, the novel of the Pacific Escape is unpopular and curious, but the theme is very easy to attract audiences' attention. While the article "Lu Han's Fan Empire" of GQ Lab has also gets a huge large number of clicks.

\section{Conclusion}

The pure literature of information age has begun to face torture of real world. The fictional world once created by literature communication begins to dissolve. The blowout of "non-fictional literature" shows great vitality. Although "non-fiction literature" still faces huge controversy, with the popularity of new media and transformation era of society, the public's attention to real space has surpassed traditional literature in a certain dimension. And even some writers have said "Our reality is more wonderful than fiction." Non-fiction literature has become an important event in new century literature, and extends new trend of literature communication. In popular culture era, the audience's education level has been greatly improved. When traditional fiction writing receives backlash, the audiences are more willing to accept true story. However, with rapid development of new media, "fragmented" reading becomes more popular. Thus, it is inevitable to spread "non-fiction literature" in context of new media.

\section{References}

1. Chen Y. Literature ecology in the context of new media from Xiuhua Yu to Yusu Fan (in Chinese). Literature Education 2019; (1): 135-137.

2. Liu Y. The dispute of "literary boundary" between poetry and folk music in the context of new media (in Chinese). Qilu Realm of Arts 2018; (2): 114-117. doi: 10.3969/j.issn.1002-2236.2018.02.024.

3. Zhu J. Difficulties and breakthroughs in the dissemination of writers' works in the context of new media (in Chinese). Literature Education 2016; (7): 102-104. 